\title{
The Effects of Earthquake Significant Duration D595 to the Earthquake Intensity Measures and the Inelastic Response of SDOF Reinforced Concrete Structure
}

\author{
Widodo Pawirodikromo ${ }^{1, *}$ \\ ${ }^{1}$ Department of Civil Engineering and Disaster Risk Management, Universitas Islam Indonesia, \\ Yogyakarta
}

\begin{abstract}
The concept of seismic intensity measures has long been discussed and has been collected by researchers among whom are by [1-6]. However, the effect of earthquake duration on the structural response has not received attention from the researcher so it has not been seen in the list of the existing seismic intensity measures. In the spectral response, for example, it has been accommodated peak value and earthquake frequency content but has not accommodated the duration of the earthquake. The effect of earthquake duration on a response, damage or collapse capacity of the structure has been done by the researchers [7-10]. The spectrally equivalent approach/control has been used by $[9,10]$., while the collapse capacity approach is cursed by [8]. The use of the classification of the earthquake frequency content as independent variables has been suggested by [7]. In this study, the classification of earthquake frequency (low frequency), earthquake duration as the independent variable and peak acceleration control have been used. Single degree of Freedom (SDOF) structures excited by 15 -earthquakes with effective durations varying between te $=6.34$ to $30.18 \mathrm{~s}$ have been used. The results showed that not all seismic intensity measure used had a strong relationship with effective duration. The earthquake effective duration has a positive relationship with the damage index but the relationship is relatively weak
\end{abstract}

\section{Introduction}

Earthquake is one the family of natural phenomena that often make great damage and losses, especially in Indonesia. In civil engineering, the earthquake will be related to the mechanism of occurrence, magnitude, depth, source to site transmission path and the influence of local soil conditions. Arriving at the site, the earthquake record physically will be presented in the form of time history and will contain the amplitude, frequency content, and duration. Based on the record, the ground motion time history can be elaborated into many types of seismic/earthquake intensity parameters/measures as presented by [1-6]. One

*Corresponding author: widodo355@gmail.com, 785110201@uii.ac.id 
of the parameters in the seismic intensity measure is the duration of earthquake ground motions.

At a glance, the duration of the earthquake ground motions can be interpreted as the total duration of the earthquake records or DT. After being examined and studied further, the more essential meaning of the earthquake duration is not the duration of earthquake record DT but the effective duration that contains the main potential energy which leads to damage of the buildings. The discussion of the earthquake duration has developed starting from the total duration, then the effective duration and then developed again into the predictive equation of earthquake duration. There have been many concepts of effective duration and predictive earthquake duration that have been proposed by the researchers. A lot of data are required for the determination of the predictive earthquake duration. Due to lack of data, relatively simple effective/significant earthquake duration was used in this study. Furthermore, the relationship between the effective earthquake duration with seismic intensity measure and its impact on the response/damage of the structure is very necessary to be investigated.

Research on the effects of ground motion duration on structural responses is very interesting and has been gaining attention from researchers [7-10]. Effect of earthquake ground motion duration on reinforced concrete (RC) building was studied by [7]. The structural model is 4-story, 2-bay reinforced concrete building located at soil D class and was designed according to ASCE 7-10 and ACI 318-11. Thirty ground accelerations were used with the duration ranging from 5 to $150 \mathrm{~s}$. All of the ground acceleration response spectrums were normalized by matching to the 5\% damped elastic design response spectrum. The peak roof/global drift and peak inter-story drift are used for the damage indicators. The result of the study shows that a large scattering of drift response is observed and there is no clear correlation between earthquake duration and damage indicator. The improvement of correlation is found whenever the ground motions are classified.

Effect of ground motion duration on earthquake-induced structural collapse was also studied by [8]. Two group of multi-story 2-D i.e the modern ductile RC frame and the older non-ductile RC frame, 3 bays steel moment resisting frame buildings (2-20 stories) were used in the analysis. The inelastic dynamic analysis is performed taking into account 76 soil motion recording, where the duration of seismic motion (based on D595) varies between $1.1-271 \mathrm{~s}$. the inelastic spectral

displacement Sdi was used as an indicator of the structural collapse aside of the maximum inter-story drift ratio. The result of the study concluded that the duration of earthquake record does not have much influence to the maximum drift response, however, the collapse capacity of the structure decreases when the duration of the record increases.

The influence of ground motion duration on the structural damage capacity of steel moment resisting frame and bridge pier has been carried out by [9]. To reduce the effect of ground acceleration amplitude, the response spectrum short duration is matched with the response spectrum of long duration earthquake so that it becomes spectrally equivalent (spectrum control). The 2-D steel 5-story moment resisting frame was used as a structural model. Besides at the ends of the beam, the plastic joints on the structural model are also allowed to occur at the ends of the columns. While the bridge pier is modeled as an SDOF structure with a plastic hinge occurring at the bottom end of the pier. The effects of P-delta and cyclic deterioration are calculated on the analysis of which deterioration algorithm according to modified Ibarra-Medina-Krawinkler has been used. The result of the investigation said that in general, the ground motion duration gives effects on the structural collapsed capacity particularly for higher structural deformations.

The main aim of this paper is to investigate the effects of the earthquake significant duration to the inelastic response of Single Degree of Freedom (SDOF) structure. In contrast to previous research which was using spectrum control, in this study, the 
acceleration control was used. All ground accelerations are normalized/equalized so that it has the same peak ground acceleration. The approach used is to reduce the variability of the effect of seismic intensity on the structure response. The inelastic response structure is quantified form of damage index.

\section{The duration of earthquake ground motions}

The duration of earthquake strong motions has gained attention from researchers for a long time [11]. After experiencing the development of the research, then the duration of earthquake strong motions, in general, can be classified into the following description.

\subsection{The Generic expression of earthquake duration}

The duration of earthquake ground motion based on this type is determined by using the acceleration, velocity or displace ment earthquake records. The earthquake duration is defined as:

a. The Bracketed Duration, $D_{b}$

Bracketed duration $\mathrm{D}_{\mathrm{b}}$ is often defined as the total time elapsed between the first and the last where the ground acceleration reach a particular threshold/specified values [12]. The Bolt's bracketed duration was defined by considering the absolute threshold value of acceleration as high as $0.05 \mathrm{~g}$ [13].

b. The Uniform Duration, Du

The uniform effective duration Du is also using a particular threshold acceleration and defined as the sum of the time intervals during which the acceleration is greater than the threshold value.[13]. The determination of this effective duration is more time consuming as compared to the Bolt's bracketed method.

c. The Significant or effective duration, Ds

The significant duration of earthquake ground motion is determined based on the accumulated energy of the acceleration represented by the integral of the square of acceleration, velocity or displacement [12]. According to [11] this earthquake duration is determined based on the total time elapsed from $5 \%$ to $95 \%$ of the integral of the acceleration and mathematically can be expressed in,

$$
D 595=t_{e}=\cdot \int_{0.05}^{0.95} a^{2} d t
$$

Where a is the ground motion acceleration.

Since the time elapsed is determined based on 5 and $95 \%$ of the integral, then the earthquake significant duration is termed as $\mathrm{D}_{\mathrm{S}-595}$ and sometimes also simply written as D595. Besides the 5 and $95 \%$ limit values, it is sometimes also used the 5-75\% limit or D575 as presented by $[9,14,15]$. To be shorter, the term significant D595 duration can also be referred to as the effective duration or $t_{e}$.

\subsection{Predictive equation of earthquake duration, DP}

In the generic expression as previously mentioned, the duration of EQ ground motion is determined based on the earthquake records. It is necessary to make an earthquake duration prediction that can be used in general which is then called the predictive equation of earthquake ground motions. There are a lot of the predictive equations of the earthquake 
duration that have been proposed by researchers. The predictive equation of earthquake duration has been proposed by [13] only by considering the source parameters. Meanwhile [15-17] introduced the predictive equation based upon the source, path and site parameters. Similar parameters for the predictive equation derivation have also been proposed by $[14,18]$ by considering the seismic stress drop. A lot of earthquake data are required in the derivation of this predictive equation.

\section{The earthquake intensity measures}

As mentioned earlier, the seismic intensity measures have been discussed, proposed and collected by researchers [1-6] for a long time in the past. In general, the seismic intensity measures can be classified into peak values, earthquake duration, intensity and seismic energy dissipation families [3]. According to [5] the seismic or ground motion intensity measure can also be classified into acceleration, spectral and velocity based families. In another side, the seismic intensity measures can also be classified in three large-families [6] i.e according to non-structural intensity measure, structural intensity measure, and structural response measure families. All of the proposed intensity measures were addressed to the capacity or damage potential of the earthquake ground motions.

Table 1. The seismic intensity measures (SIM)

\begin{tabular}{|c|l|c|c|l|c|}
\hline No & \multicolumn{1}{|c|}{$\begin{array}{c}\text { Intensity } \\
\text { measures }\end{array}$} & Formula & No & $\begin{array}{c}\text { Intensity } \\
\text { measure }\end{array}$ & Formula \\
\hline 1 & $\begin{array}{l}\text { Arias } \\
\text { Intensity, } \mathrm{I}_{\mathrm{A}}\end{array}$ & $I_{a}=\frac{\pi}{2 . g} \int_{0}^{t_{t}} a^{2} d t$ & 5 & $\begin{array}{l}\text { Potential } \\
\text { Distruc } \\
\text { tiveness, } \mathrm{P}_{\mathrm{D}}\end{array}$ & $P_{D}=\frac{I_{a}}{v_{o}{ }^{2}}$ \\
\hline 2 & $\begin{array}{l}\text { Housner } \\
\text { Intensity, } \mathrm{IH}_{\mathrm{H}}\end{array}$ & $I_{h}=\int_{0.1}^{2.5} P S V d t$ & 6 & $\begin{array}{l}\text { Park-Ang Char. } \\
\text { Intensity, } \mathrm{I}_{\mathrm{pa}}\end{array}$ & $I_{P-A}=(R M S)^{0.66} . t_{e}^{0.50}$ \\
\hline 3 & $\begin{array}{l}\text { Earthquake } \\
\text { Power, } \mathrm{P}_{\mathrm{E}}\end{array}$ & $P_{E}=\frac{1}{t e} \int_{0.05}^{0.95} a^{2} d t$ & 7 & $\begin{array}{l}\text { Riddel \& } \\
\text { Intensity, } \mathrm{I}_{\mathrm{rg}}\end{array}$ & $I_{R-G}=(P G V)^{0.66} t_{e}^{0.33}$ \\
\hline 4 & $\begin{array}{l}\text { Root Mean } \\
\text { Square, RMS }\end{array}$ & $R M S=\sqrt{P_{E}}$ & 8 & $\begin{array}{l}\text { Fajfar Intensity, } \\
\mathrm{I}_{\mathrm{f}}\end{array}$ & $I_{F}=(P G V) . t_{e}{ }^{0.25}$ \\
\hline
\end{tabular}

The Input Energy, $\mathrm{E}_{\mathrm{I}}$ is presented in the form,

$$
\int_{0}^{t_{d}} m \ddot{y}_{t} d y=\int_{0}^{t_{d}} m \ddot{y} d y+\int_{0}^{t_{d}} c \dot{y} d y+\int_{0}^{t_{d}} k y d y
$$

Where $\mathrm{m}, \mathrm{c}$ and $\mathrm{k}$ are mass, damping coefficient and stiffness respectively, $\ddot{\mathrm{y}}, \mathrm{y}$ and y are acceleration, velocity and displacement. 
Meanwhile the absorb energy equivalent velocity [1], VE

$$
V_{E}=\sqrt{\frac{2 \cdot E_{d e}}{m}}
$$

Where $E_{d s}$ is sum of the viscous energy $E_{v}$ and hysteretic energy $E_{h}, m$ is mass of the structure.

\section{Inelastic response and Damage Index}

The level of structural response is affected by the level of ground acceleration. When the ground acceleration exceeded a particular level, the response structure will undergo the inelastic phase. Since the structural response is no longer elastic the structure starts to damage in which due to cyclic loads, the relationship between force and displacement is presented in the form of hysteretic loops. The hysteretic loops can be defined based on flexural dominated, shear dominated or axial load dominated. There are dozens of hysteretic loops that can be applied in the analysis $[19,20]$ where the behavior of the model is affected by several aspects. In this study, the modified Takeda flexural dominated model is used accompanied by its particular common coefficients. This model accommodates stiffness degradation but not on the strength degradation.

To be more understandable the phenomena, the qualitative expression of the element's damage then to be transferred into a quantitative formulation. In line with hysteretic models, there are a lot of damage index formulations that have been proposed researchers [21-23] and all of them are following the behavior of its hysteretic loops. In this study, three concepts of element damage based on ductility ratio, deformation-based and ductile based [22] has been used and is presented as,

$$
\begin{gathered}
D I=\frac{\mu_{m}}{\mu_{u}} \\
D I=\frac{\mu_{m}-1}{\mu_{u}-1} \\
D I=\frac{d_{m}}{d_{u}}+\beta \frac{\int d E}{F_{y} \cdot d_{u}}
\end{gathered}
$$

Where $d_{m}$ and $d_{u}$ are maximum and ultimate displacement, $\beta$ is cyclic parameter, $F_{y}$ is yield force and $\mathrm{E}$ is dissipated hysteretic energy.

In the SDOF inverted pendulum structure, according to [24] the relationship between the displacement and the curvature ductility is presented in the relation,

$$
\mu_{\phi}=1+\frac{\left(\mu_{\Delta}-1\right)}{3 .\left(L_{p} / L\right)\left\{1-0.5 .\left(L_{p} / L\right)\right\}}
$$

Where $\mathrm{L}$ is length of the member, $\mathrm{L}_{\mathrm{p}}$ is the length of plastic hinge and can be determined by [24]

$$
L_{p}=0.08 \cdot L+0.0228 . d_{p} \cdot f_{y}
$$

Where $d_{p}$ is the longitudinal bar diameter and $f_{y}$ is the steel yield strength. 


\section{Method of Investigation}

\subsection{Structural model and material properties}

The structural model is a single degree of freedom (SDOF) reinforced concrete structure, which is modeled as an inverted pendulum. The concrete compressive strength is $22.5 \mathrm{MPa}$ and the steel yield strength $385 \mathrm{MPa}$ is assumed. The equivalent inverted pendulum has a height of $3.20 \mathrm{~m}$ with a structural mass of $73.4 \mathrm{kgf} . \mathrm{s} 2 / \mathrm{m}$ and the equivalent column stiffness is $39837 \mathrm{kgf} / \mathrm{s}$. The ultimate flexural moment that can be resisted by the column is 45.48 $\mathrm{tfm}$. The base of the column is assumed to be fixed at the level of the ground surface.

\subsection{Earthquake ground excitations}

The structural model is then shaken by a series of ground accelerations that have different effective duration te. The effective duration of earthquake acceleration is then used as an independent variable in this study. This study will examine the effects of earthquake duration on the inelastic response of the structure. To reduce the variability of the amplitude effects, all the ground accelerations then to be isolated/normalized so that the peak ground acceleration (PGA) of all earthquakes to become $0.224 \mathrm{~g}$. The earthquake data used in this study is as shown in Table 1. The quakes used are the 1979 Cayote Lake (CL), the 1984 Morgan Hill (MH), the 1979 El Centro (EL), the 1989 Loma Prieta (LP) 1989 and the 1986 Palm Spring (PS) earthquakes. As clearly shown in Table 1 that the effective duration of earthquake ground acceleration from shallow crustal events varies from te $=6.34 \mathrm{~s}$ to te $=$ 30.18 s. The acceleration to velocity ratio (A/V ratio) appears in Table 1 is used to identify the earthquake frequency content. Since almost all of the A/V ratio less than 0.80 , it means that almost all of the earthquakes are fall in low-frequency content [25].

Table 2. The earthquake data

\begin{tabular}{|c|l|c|c|c|c|}
\hline No & Earthquake & A/V ratio & $\mathrm{t}_{\mathrm{e}}(\mathrm{s})$ & $\mathrm{Tsp}(\mathrm{s})$ & $\mathrm{PSA}(\mathrm{g})$ \\
\hline 1 & CLGoEW & 0.441 & 6.34 & 1.375 & 0.430 \\
\hline 2 & CLGoNS & 0.645 & 7.71 & 0.660 & 1.020 \\
\hline 3 & MHVycEW & 0.688 & 8.67 & 0.550 & 0.765 \\
\hline 4 & MHAndNS & 0.523 & 10.41 & 0.955 & 0.788 \\
\hline 5 & EL79NpNS & 0.405 & 11.42 & 0.305 & 0.649 \\
\hline 6 & MHGo3EW & 0.398 & 12.94 & 0.445 & 0.919 \\
\hline 7 & PSDsEW & 0.860 & 14.84 & 0.310 & 0.800 \\
\hline 8 & EL79Cb140 & 0.554 & 16.50 & 0.690 & 0.558 \\
\hline 9 & LPAoNS & 0.255 & 16.74 & 2.115 & 0.990 \\
\hline 10 & LPEmyEW & 0.316 & 17.77 & 2.340 & 0.617 \\
\hline 11 & EL79CrxNS & 0.648 & 21.88 & 0.725 & 0.704 \\
\hline 12 & LPCapNS & 0.756 & 23.38 & 0.740 & 0.842 \\
\hline 13 & MHGo2EW & 0.579 & 26.28 & 0.505 & 0.965 \\
\hline 14 & EL79EI23 & 0.227 & 28.30 & 0.290 & 0.882 \\
\hline 15 & MHHvrNS & 0.623 & 30.18 & 0.960 & 0.840 \\
\hline
\end{tabular}




\subsection{The instrument}

The inelastic dynamic analysis program for the SDOF structure has been written. The inelastic cyclic force-deformation of the RC structure is assumed to behave ductile manner and can be imitated by using the Modified Takeda hysteretic model. In maintaining the accuracy of the numerical process, the time steps as small as $0.01 \mathrm{~s}$ were used. The main outputs of the program are the structural horizontal displacement, the restoring force, the plastic hinge flag, the viscous, hysteretic, kinetic and strain energy as well as the stiffness ratio.

\section{Structural Response}

\subsection{Pseudo Spectral Acceleration (PSA) and Pseudo Spectral Velocity (PSV).}

The (PSA) and PSV of the selected ground acceleration are presented in Fig. 1) and Fig.2). As shown in Fig.1) that most of the earthquake possesses spectral peak period less than 1second. However there are 3-EQ possesses very low frequency with spectral peak period higher than 1-second i.e. $\mathrm{A} / \mathrm{V}=0.255(\mathrm{Ts}=2.12 \mathrm{~s}), \mathrm{A} / \mathrm{V}=0.316(\mathrm{Ts}=2.34 \mathrm{~s})$ and $\mathrm{A} / \mathrm{V}=$ $0.44(\mathrm{Ts}=1.38 \mathrm{~s})$ and all of them can be found at Table 1 .

Meanwhile, the PSV of all considered earthquakes is presented in Fig.2). Since PSV is strongly correlated with PSA then it clearly appears in the figure that the earthquake with very low frequency (wide range of frequency bandwidths) possesses higher PSV. In further, the area of PSV will affect to the Housner's intensity $I_{h}$.

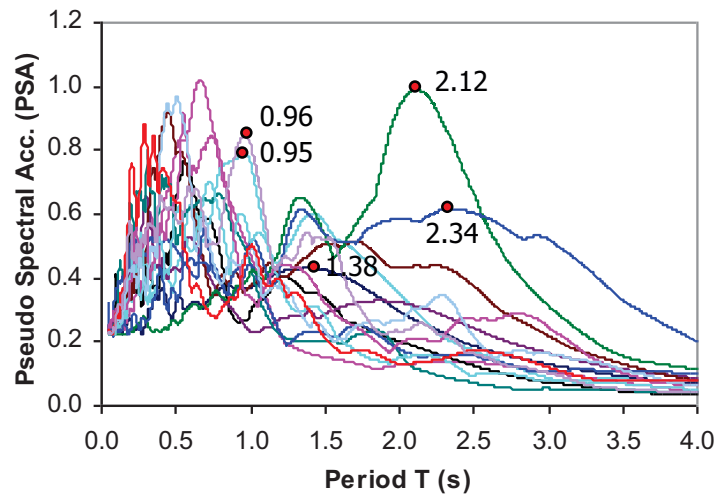

Fig.1 . Pseudo Spectral Acceleration (PSA)

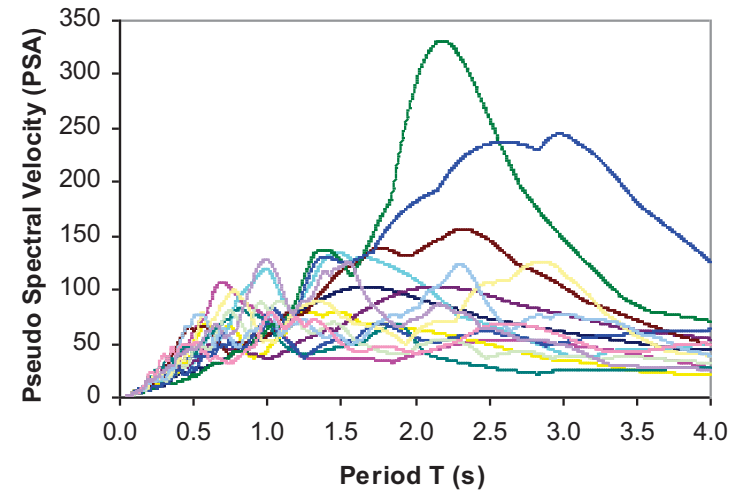

Fig. 2. Pseudo Spectral Velocity (PSV) 


\subsection{Typical Structural Response}

An example of the inelastic response of the structure subjected to the Morgan Hill earthquake (MHGo3EW) is presented in Fig.3). The time history of the MHGo3EW earthquake is presented in Fig.3a), meanwhile the horizontal displacement of the mass is presented in Fig.3b). As shown in the figure, the pattern of the structural displacement exactly follows the pattern of the earthquake excitation. The maximum horizontal displacement is $2.57 \mathrm{~cm}$ or equivalent with $0.801 \%$ drift ratio. The displacement ductility time history is presented in Fig.3.c). The maximum displacement ductility $\mu_{\Delta}=7.71$, is relatively high value for ductile structure assumption.

The dissipated energy time history is presented in Fig.3d). As presented in Eq.2) that in the fixed structure all of the input energy $E_{i}$ is converted to be kinetic $E_{k}$, strain $E_{s}$, viscous $E_{v}$ and hysteretic energy $E_{h}$. As shown in the figure that at the end of the integration time, the kinetic and the strain energy become a zero since the velocity and the displacement of the mass back to the original position or zero value. The remaining input energy is totally dissipated by viscous and hysteretic energy. The dissipated hysteretic energy is presented visually by the hysteretic loops as presented in Fig.3e). As shown in the figure that the yield displacement $\Delta_{\mathrm{y}}=0.333 \mathrm{~cm}$, the yield force $\mathrm{F}_{\mathrm{y}}=13250 \mathrm{kgf}$ and the maximum displacement of the structure will be depended on the exciting force.

The time history of structural damage index DI according to Eq.4) is presented in Fig.3f). As shown in the figure that the negative damage index is only signed since the displacement of the structure can be a negative value/sign. The maximum value of damage index DI $=1.38>1.0$, it means that according to $[10,22]$ the structure is expected to collapse. Other structural responses such as structural drift ratio, curvature ductility, number of plastic hinges and stiffness degradation ratio are not presented in this section since the limitation of space.

\subsection{Relationship between te and $A / V$ ration with seismic intensities}

The relationship between effective duration te and the seismic intensity measures as written in Table 4 is presented in Fig.4) and the coefficient correlation of its relationship is presented in Table 3. As clearly shown in the figure and the table that only the Arias intensity Ia and the Park-Ang intensity Ip-a [4] which has a strong and very strong relationship with the effective earthquake duration te. This result is caused by the fact that the Park and Ang intensity as presented in Table 2 is directed affected by the effective duration te and the Arias intensity Ia is influenced by the duration either total duration DT or the effective duration te.

Meanwhile, the relationship between the $\mathrm{A} / \mathrm{V}$ ratio and the seismic intensity measure is presented in Fig.5) and Table 3. It is clear that only the Fajfar intensity $\mathrm{I}_{\mathrm{f}}$ [4] and the Riddel and Garcia intensity $\mathrm{I}_{\mathrm{r}-\mathrm{g}}[4]$ which has a strong relationship with the A/V ratio. This result is found because the intensities as presented in Table 1 is directly affected by PGV or related to the ground velocity time history. 

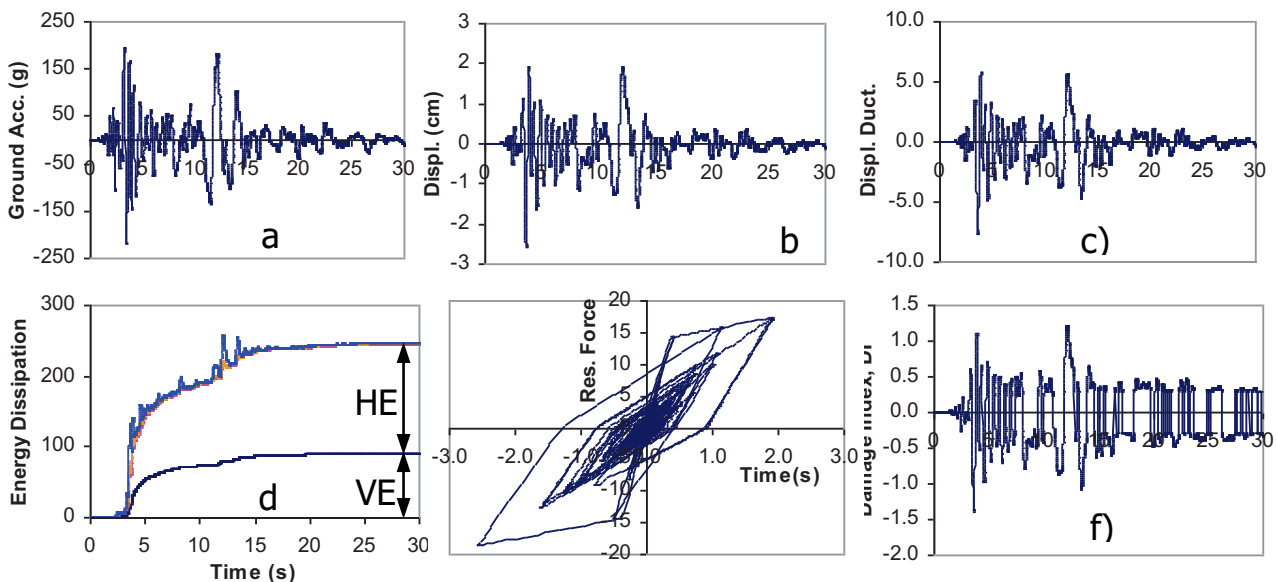

Fig.3. The typical of inelastic structural response

Table 3. The coefficient correlation

\begin{tabular}{|c|c|c|c|c|c|c|c|c|}
\hline \multirow{2}{*}{ Ind. Var } & \multicolumn{8}{|c|}{ Coefficient Correlation } \\
\cline { 2 - 9 } & $\mathrm{I}_{\mathrm{A}}$ & $\mathrm{I}_{\mathrm{H}}$ & $\mathrm{PE}_{\mathrm{E}}$ & $\mathrm{P}_{\mathrm{D}}$ & $\mathrm{V}_{\mathrm{E}}$ & $\mathrm{IP}_{\mathrm{P}-\mathrm{A}}$ & $\mathrm{I}_{\mathrm{R}-\mathrm{G}}$ & $\mathrm{I}_{\mathrm{F}}$ \\
\hline D595 = $\mathrm{t}_{\mathrm{e}}$ & 0.819 & 0.051 & 0.482 & 0.071 & 0.579 & 0.611 & 0.498 & 0.213 \\
\hline Correlation & $\begin{array}{c}\text { very } \\
\text { strong }\end{array}$ & $\begin{array}{c}\text { very } \\
\text { weak }\end{array}$ & moderate & $\begin{array}{c}\text { very } \\
\text { weak }\end{array}$ & moderate & strong & moderate & weak \\
\hline $\mathrm{A} / \mathrm{V}$ & 0.032 & 0.566 & 0.118 & 0.152 & 0.351 & 0.057 & 0.751 & 0.825 \\
\hline Correlation & $\begin{array}{c}\text { very } \\
\text { weak }\end{array}$ & moderate & $\begin{array}{c}\text { very } \\
\text { weak }\end{array}$ & $\begin{array}{c}\text { very } \\
\text { weak }\end{array}$ & weak & $\begin{array}{c}\text { very } \\
\text { weak }\end{array}$ & strong & $\begin{array}{c}\text { very } \\
\text { strong }\end{array}$ \\
\hline
\end{tabular}
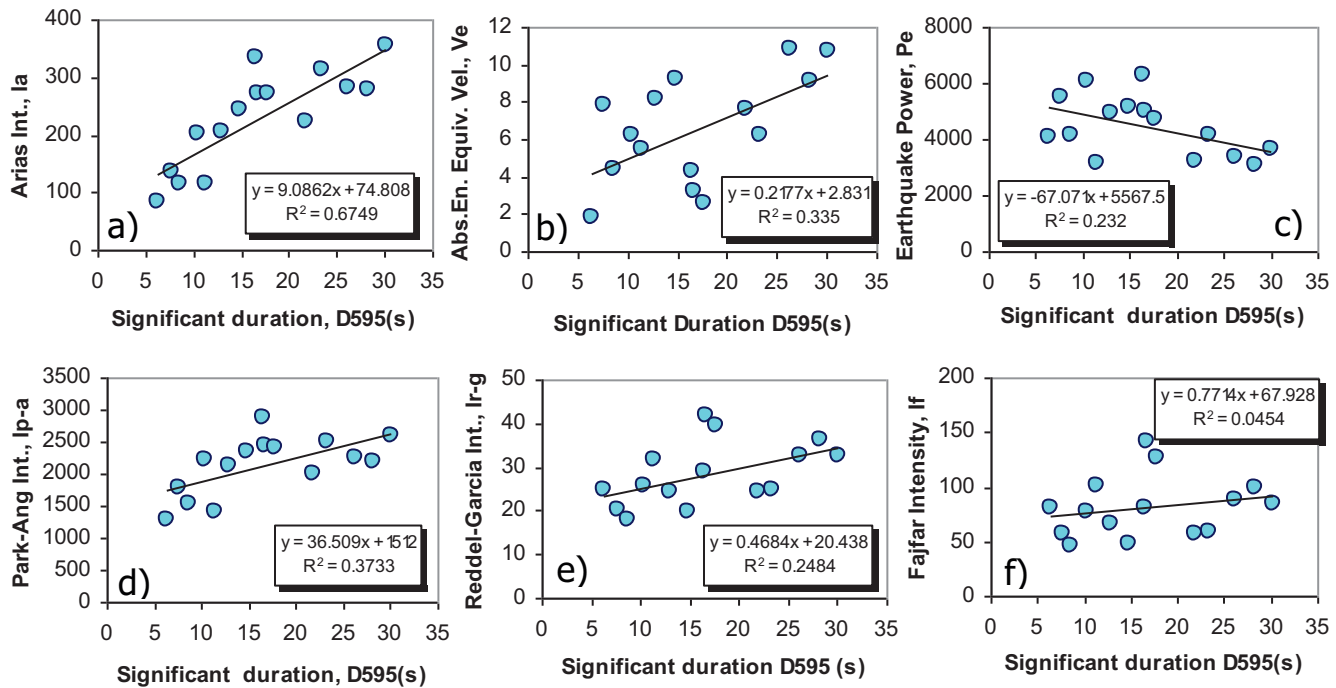

Fig.4. Relationship between significant duration D595 and seismic intensity measure 

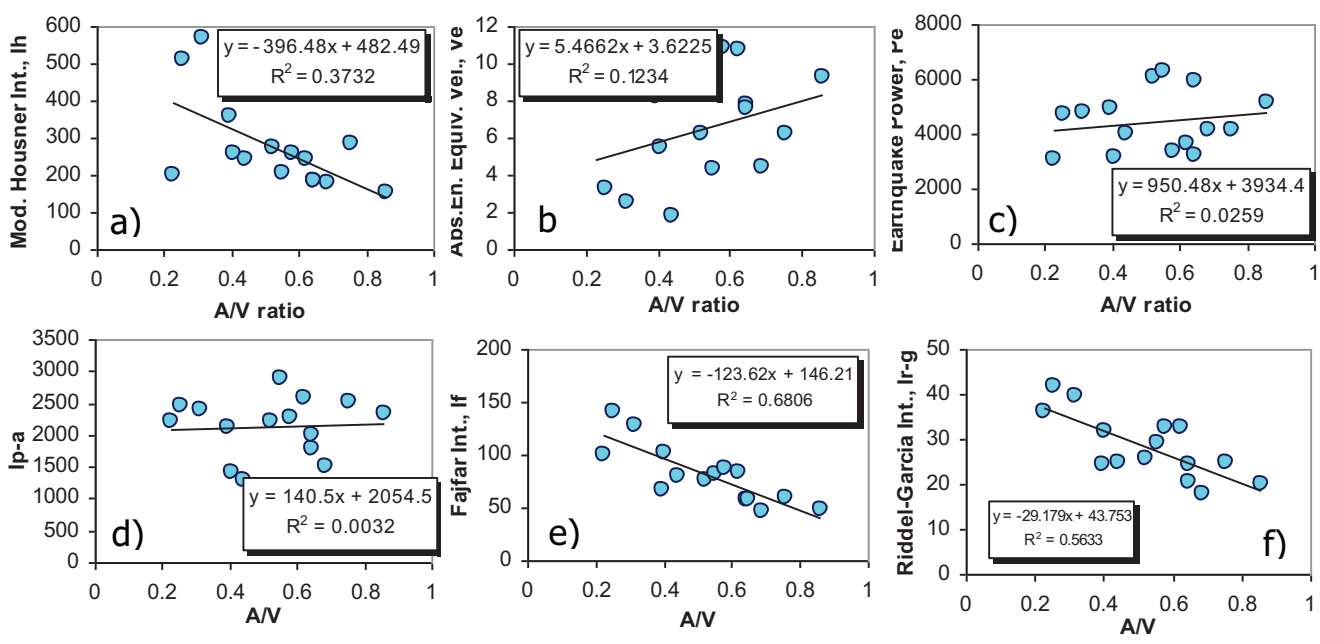

Fig.5. Relationship between A/V ratio and seismic intensity measure

\subsection{Effect of te and other aspects to damage index DI}

This is the main objective of the study, in which the inelastic structural response as written in Table 5 is presented quantitatively by the damage index (DI). As presented in Eqs.4), 5) and 6) three concept of reinforced concrete damage index was used. The plot between the effective duration of earthquake ground motion te and the Park-Ang damage index is presented in Fig.6a) and its comparison to ductility damage index is presented in Fig.6b). As shown in the figure that positive (pos) and negative (neg) as written in Box is only sign based on the positive and negative sign of the computed displacement.

It is clearly shown in the figure that the damage index DI varies from $0.29-2.08$ and according to [10 ] when DI $>1.0$ the structure has already in the collapsed state. As shown in the figure between the effective duration of earthquake ground acceleration $t_{\mathrm{e}}$ and the damage index DI possesses positive correlation. It means that the longer the effective duration of earthquake ground acceleration $t_{e}$, the higher the structural damage index DI will be likely. This result is similar to the result as presented by [26] The coefficient correlation of the relationship varies from $r=0.276-0.371$. Even though it has a positive correlation, however, according to [ 27 ], the strength of the correlation between $t_{\mathrm{e}}$ and DI falls in the category of a weak level.
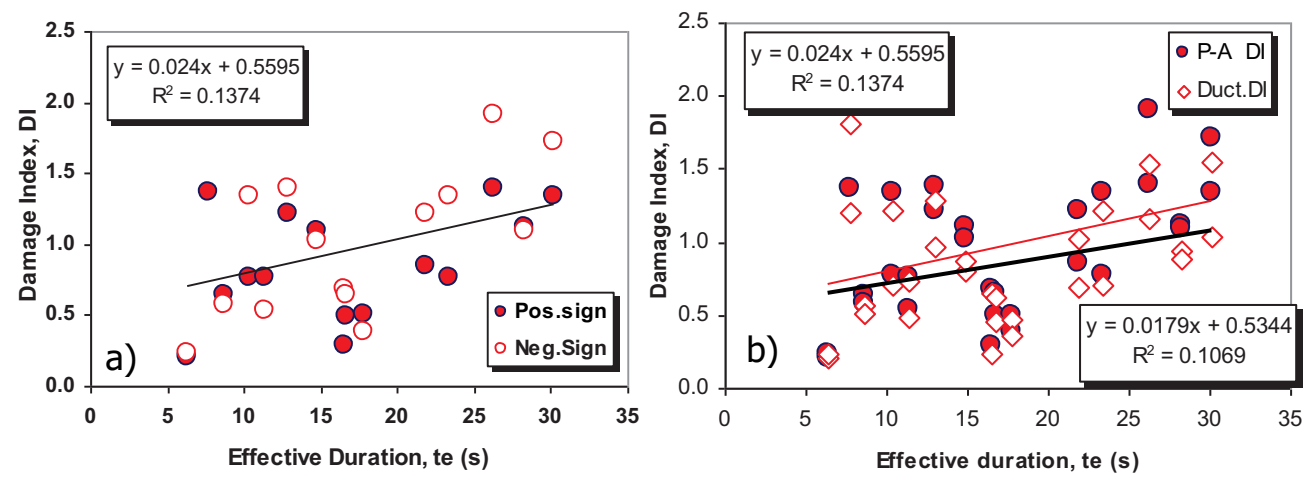

Fig. 6. Relationship between $t_{\mathrm{e}}$ and damage index; a) Park-Ang, b) Park-Ang and ductility concept 


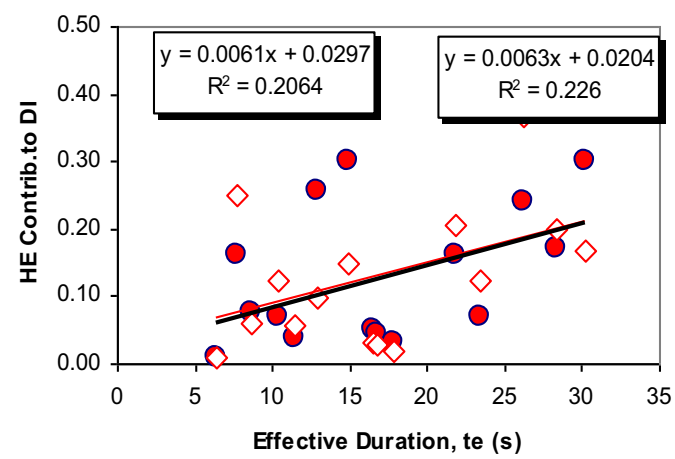

Fig. 7. Eff. duration te vs. HE contribution to DI

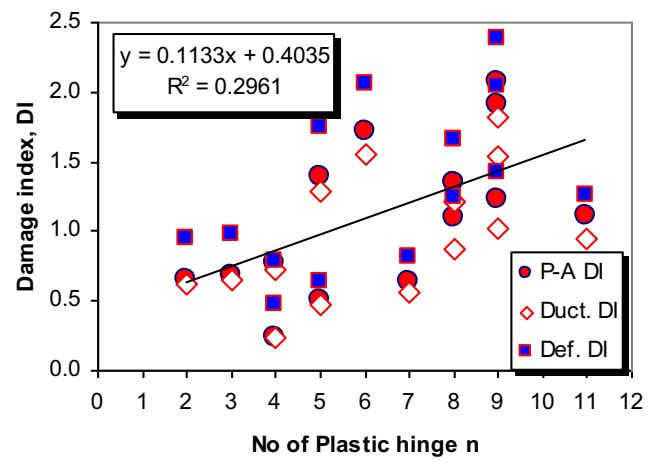

Fig.8. No. plastic .hinges vs. damage index DI

Hysteretic energy HE contribution to damage index DI is presented in Fig.7). As shown in the figure, the contribution of energy HE to the damage index varies from $0.9 \%-36.8$ $\%$, hence, the damage index of the ductile structure DI is dominated by the contribution of the deformation aspect. In the figure also appears that the effective duration $t_{\mathrm{e}}$ contributes positive correlation to the $\mathrm{HE}$ contribution. The relationship gives the correlation coefficient $r=0.454-0.475$ or possesses a moderate strength of correlation. Relationship of another aspect i.e. between the numbers of plastic hinge $n$, and the DI is presented in Fig.8). As appears in the figure the Duct.DI, Def. DI and P-A DI refers to ductility base damage index (Eq.4), deformation based damage index (Eq.5) and Park-Ang damage index (Eq.6). Similar to previous results, between numbers of plastic hinge $n$, and damage index provides a positive correlation with coefficient correlation $r=0.511$ or moderate strength of correlation.

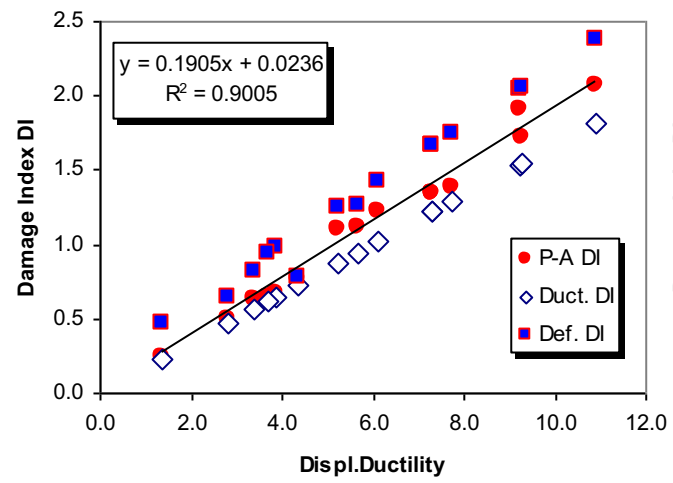

Fig. 9. Displ. duct $\mu_{\Delta}$ vs. damage index DI

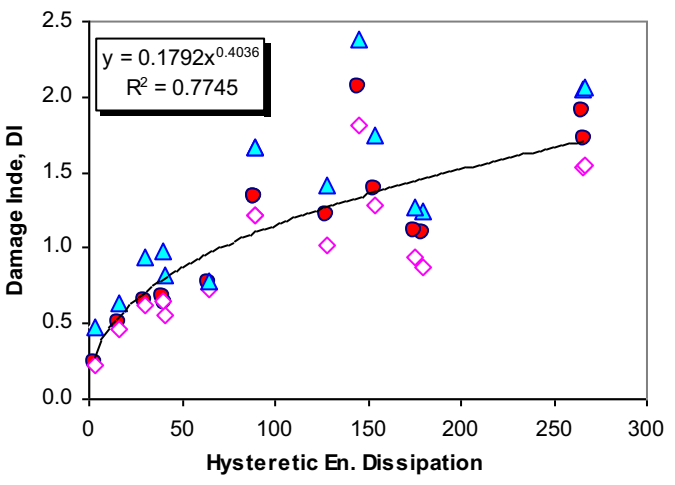

Fig.10. Hyst. Energy vs. damage index,DI

The displacement ductility $\mu_{\Delta}$ and hysteretic energy dissipation are other aspects and can be correlated with the damage index. The relationship between $\mu_{\Delta}$ with DI is presented in Fig.9). It appears in the picture that its relationship is linearly strong with correlation coefficient $r=0.9489$. Meanwhile, the relationship between $\mu_{\Delta}$ and hysteretic energy dissipation is presented in Fig.10). It is shown in the picture that the relationship is not linear but tends to be dispersed with correlation coefficient $r=0.88$. The relationship as presented in Figs.9) and 10) supports the result as presented in Fig. 7) that in the ductile structure, the damage index is dominated by the deformation aspect.

The relationship between the peak of pseudo-spectral acceleration (PSA) and DI is illustrated in Fig.11). As clearly shown in the figure that the peak PSA also possesses a 
strong relationship with DI as they have correlation coefficient $r=0.6944$. It is possible to determine the new seismic intensity measures as a function of the effective duration $t_{e}$, the A/V ratio and the peak PSA to cause a strong relationship with the structural damage index DI. Meanwhile, the absorb energy equivalent velocity $\mathrm{V}_{\text {aev }}$ as defined in Eq.3) and its relationships with the displacement ductility $\mu_{\Delta}$ are depicted in Fig.12). The result indicated that as the displacement ductility $\mu_{\Delta}$ increases, the contribution of viscous and hysteretic energy to the absorb energy equivalent velocity $\mathrm{V}_{\mathrm{E}}$ also increase. It appears also in the figure that the contribution of the hysteretic is higher than the viscous energy. This result confirms to the previous result (Fig.3) where the dissipated hysteretic energy will be higher than the viscous energy, particularly for the higher structural response. 
Table 4. Earthquakes and Seismic Intensity Measure (SIM)

\begin{tabular}{|c|c|c|c|c|c|c|c|c|c|c|c|c|}
\hline No & Earthquake & te $(s)$ & $\operatorname{PSA}(\mathrm{g})$ & Ia & $\operatorname{Ih}(\mathrm{m})$ & $\mathrm{Ih}$ & $\mathrm{Pe}$ & vo & $\mathrm{Pd}$ & Ip-a & Ird-g & If \\
\hline 1 & CLGoEW & 6.34 & 0.430 & 82.420 & 242.650 & 158.105 & 3969.680 & 1.033 & 77.283 & 1280.046 & 24.567 & 80.550 \\
\hline 2 & CLGoNS & 7.71 & 1.020 & 136.455 & 183.760 & 118.353 & 5906.788 & 0.981 & 141.773 & 1779.104 & 20.359 & 57.705 \\
\hline 3 & MHVycEW & 8.67 & 0.765 & 114.695 & 180.647 & 133.727 & 4128.778 & 1.515 & 49.996 & 1516.616 & 17.853 & 45.924 \\
\hline 4 & MHAndNS & 10.41 & 0.788 & 203.066 & 276.110 & 146.016 & 6088.112 & 1.790 & 63.376 & 2223.757 & 25.839 & 76.815 \\
\hline 5 & EL79NpNS & 11.42 & 0.649 & 113.917 & 257.047 & 150.523 & 3113.294 & 2.065 & 26.704 & 1408.472 & 31.532 & 101.491 \\
\hline 6 & MHGo3EW & 12.94 & 0.919 & 204.750 & 356.821 & 223.732 & 4938.409 & 0.809 & 312.883 & 2119.129 & 24.411 & 66.744 \\
\hline 7 & PSDsEW & 14.84 & 0.800 & 244.197 & 155.070 & 115.496 & 5135.748 & 2.238 & 48.776 & 2337.059 & 19.906 & 47.347 \\
\hline 8 & EL79Cb140 & 16.5 & 0.558 & 333.917 & 204.222 & 117.981 & 6316.128 & 2.565 & 50.771 & 2877.930 & 28.981 & 81.462 \\
\hline 9 & LPAoNS & 16.74 & 0.990 & 269.718 & 511.806 & 320.563 & 4737.163 & 0.413 & 1580.662 & 2443.236 & 41.809 & 141.425 \\
\hline 10 & LPEmyEW & 17.77 & 0.617 & 269.718 & 566.071 & 262.576 & 4755.898 & 0.482 & 1161.303 & 2407.035 & 39.356 & 127.135 \\
\hline 11 & EL79CrxNS & 21.88 & 0.704 & 223.545 & 182.521 & 126.069 & 3188.697 & 2.341 & 40.798 & 1984.877 & 24.181 & 57.698 \\
\hline 12 & LPCapNS & 23.38 & 0.842 & 312.409 & 282.260 & 158.720 & 4170.376 & 2.324 & 57.864 & 2509.306 & 24.896 & 59.312 \\
\hline 13 & MHGo2EW & 26.28 & 0.965 & 283.229 & 257.912 & 161.362 & 3363.638 & 1.360 & 153.192 & 2264.225 & 32.782 & 87.401 \\
\hline 14 & EL79EI23 & 28.3 & 0.882 & 278.825 & 197.760 & 115.472 & 3074.974 & 2.719 & 37.702 & 2196.718 & 36.139 & 99.453 \\
\hline 15 & MHHvrNS & 30.18 & 0.840 & 353.338 & 243.357 & 183.869 & 3653.991 & 0.998 & 354.557 & 2581.875 & 32.648 & 83.907 \\
\hline
\end{tabular}


Table 5. Earthquakes and response of structure

\begin{tabular}{|c|c|c|c|c|c|c|c|c|c|c|c|c|}
\hline No & Earthquake & Tst(s) & Inp.En. & Displ. Duct & Curv.Duct & Pl.Hinge & Visc. En & Hyst.En. & Vaev & Duct.DI & P-Ang DI & Def. DI \\
\hline 1 & CLGoEW & 0.27 & 9.350 & 1.383 & 5.678 & 4 & 9.320 & 2.920 & 1.666 & 0.231 & 0.239 & 0.477 \\
\hline 2 & CLGoNS & 0.27 & 224.460 & 10.884 & 32.300 & 9 & 78.660 & 144.810 & 3.169 & 1.814 & 2.065 & 2.377 \\
\hline 3 & MHVycEW & 0.27 & 72.210 & 3.367 & 10.480 & 7 & 30.590 & 41.310 & 9.788 & 0.561 & 0.636 & 0.819 \\
\hline 4 & MHAndNS & 0.27 & 142.320 & 7.306 & 22.274 & 8 & 52.410 & 89.360 & 5.221 & 1.218 & 1.341 & 1.661 \\
\hline 5 & EL79NpNS & 0.27 & 109.080 & 4.360 & 10.414 & 4 & 43.590 & 64.630 & 9.096 & 0.727 & 0.766 & 0.777 \\
\hline 6 & MHGo3EW & 0.27 & 246.570 & 7.727 & 23.454 & 5 & 91.360 & 154.190 & 14.732 & 1.288 & 1.387 & 1.745 \\
\hline 7 & PSDsEW & 0.27 & 315.190 & 5.231 & 16.461 & 8 & 134.070 & 179.340 & 42.664 & 0.872 & 1.099 & 1.246 \\
\hline 8 & EL79Cb140 & 0.27 & 67.800 & 3.878 & 12.670 & 3 & 26.520 & 40.300 & 41.904 & 0.646 & 0.678 & 0.976 \\
\hline 9 & LPAoNS & 0.27 & 38.610 & 3.698 & 12.165 & 2 & 7.890 & 30.460 & 28.564 & 0.616 & 0.646 & 0.940 \\
\hline 10 & LPEmyEW & 0.27 & 23.630 & 2.796 & 7.952 & 5 & 7.270 & 16.010 & 19.299 & 0.466 & 0.499 & 0.639 \\
\hline 11 & EL79CrxNS & 0.27 & 210.810 & 6.103 & 18.904 & 9 & 81.800 & 128.030 & 54.990 & 1.017 & 1.222 & 1.421 \\
\hline 12 & LPCapNS & 0.27 & 142.320 & 7.306 & 22.274 & 8 & 149.900 & 254.060 & 33.426 & 1.218 & 1.341 & 1.661 \\
\hline 13 & MHGo2EW & 0.27 & 436.490 & 9.230 & 27.666 & 9 & 167.020 & 265.420 & 58.867 & 1.538 & 1.906 & 2.046 \\
\hline 14 & EL79EI23 & 0.27 & 310.450 & 5.652 & 16.714 & 11 & 132.380 & 175.450 & 57.075 & 0.942 & 1.114 & 1.264 \\
\hline 15 & MHHvrNS & 0.27 & 420.570 & 9.290 & 27.835 & 6 & 152.610 & 266.660 & 30.421 & 1.548 & 1.718 & 2.058 \\
\hline
\end{tabular}




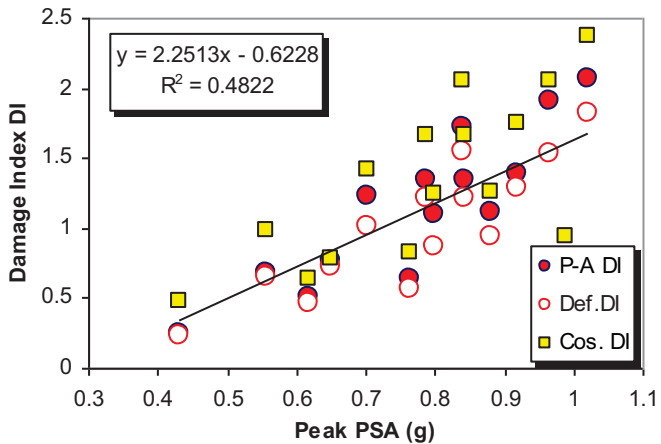

Fig. 11. The peak PSA vs. damage index DI

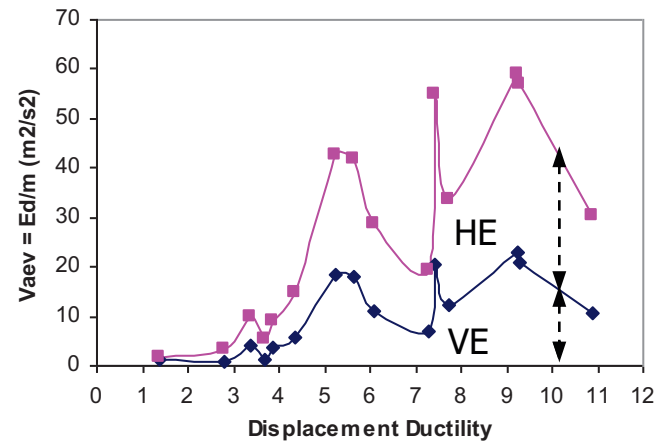

Fig.12. The displ. ductility vs. the $\mathrm{V}_{\text {aev }}$

\subsection{Effects of extremely low frequency content to the structural response}

As presented in Table 4 that earthquake No.1, 8, 9 and 10 possesses relatively high seismic intensity measure, particularly as indicated by the Housner intensity $\mathrm{I}_{\mathrm{h}}$, the earthquake power $\mathrm{P}_{\mathrm{e}}$, potential destructiveness $\mathrm{P}_{\mathrm{d}}$, the Park-Ang intensity Ip-a, the Riddel-Garcia intensity $I_{r-g}$ and the Fajfar intensity $I_{f}$. However, as written in Table 5) the structural response subjected to this earthquakes are relatively small. This result is caused by a relatively rigid structure $(\mathrm{Ts}=0.27 \mathrm{~s}$ ) that it was shaken by so low-frequency content (as indicated by a low value of the A / V ratio of the LPAoEW earthquake) and high structural fundamental period $(\mathrm{Tsp}=2.115 \mathrm{~s})$. In this case, the frequency ratio $r=\Omega / \omega=0.127$, is relatively low value and far away from the resonant response and therefore the earthquake only causes low structural damage index.

Another reason is that there are only a few occurrences of plastic hinge illustrated by Fig.13a). Fig.13a) is the structural response (displacement, number of plastic hinge and hysteretic energy dissipation) under the Loma Prieta earthquake (LPAoNS). As shown in the figure or as presented in Table 5) that only 2-plastic hinges occur during the loading history. Only with 2 occurrences of the plastic hinge and accompanied by low displacement ductility it leads to relatively low hysteretic energy dissipation as shown in Table 5). They are all reasons why it only causes a low value of structural damage index.

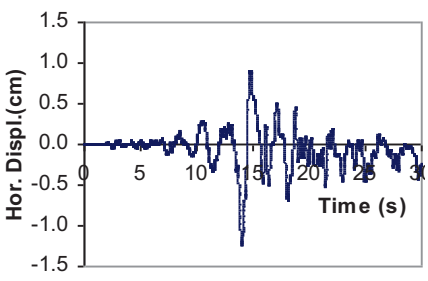

a)

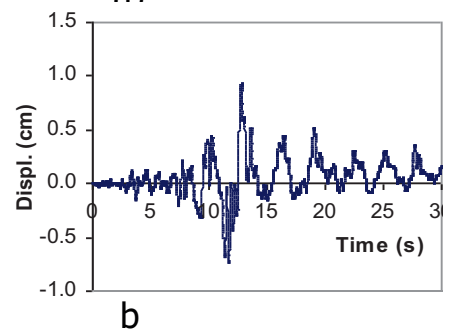

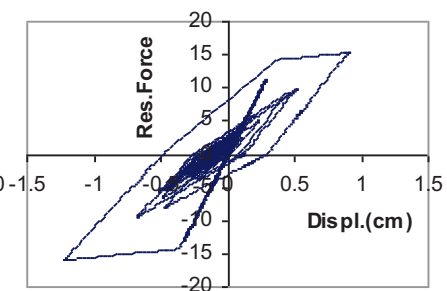
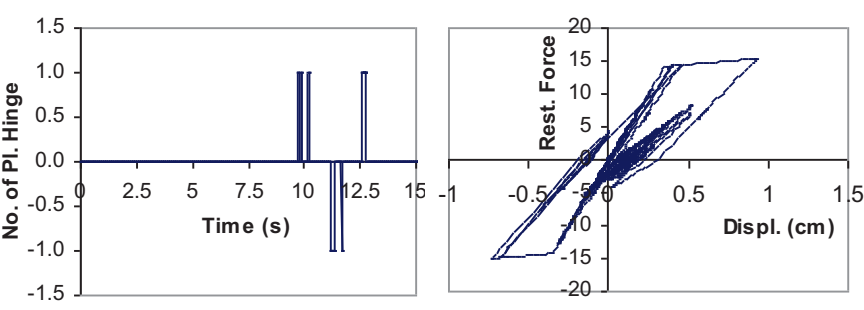

Fig.13. The structural response: a) by the LPAoEW earthquake; b) by the LPEmyEW earthquake 
The other structural response caused by very low earthquake frequency content i.e. by the other Loma Prieta (LPEmyEW) earthquake is presented in Fig.13b). Similar to as presented in Table 5) that the structural response is relatively small even though more plastic hinges occurred in the structure i.e. $n=5$. As presented in Table 5), this earthquake only causes relatively low displacement ductility $\mu_{\Delta}$ and dissipated hysteretic energy. As shown in the figure, the displacement of the structure occurs only /dominated on one side only (positive sign). This response, of course, will affect the shape and the area of dissipated hysteretic energy. Again, the lower values of displacement ductility and dissipated hysteretic energy will cause smaller a structural response.

\section{Conclusions}

Inelastic dynamic analysis of SDOF structures due to low-frequency earthquakes with significant/effective duration variations has been made. The earthquakes used in this study are still low-medium duration because they are taken from shallow crustal earthquake events. The earthquakes used in this study only have a low to medium significant/effective duration because the earthquakes are only taken from the shallow crustal earthquake events. The results of the study can be summarized as follows.

The Significant or the effective duration does not have a strong relationship with all the seismic intensity used. The significant duration has only a strong and strong relationship with Park-Ang and Arias intensity. The significant duration is related to moderate correlation with Earthquake Power $\mathrm{P}_{\mathrm{E}}$, the absorb energy equivalent velocity $\mathrm{V}_{\mathrm{E}}$ and Riddel-Garcia intensity, $\mathrm{I}_{\mathrm{r}-\mathrm{g}}$ Meanwhile the $\mathrm{A} / \mathrm{V}$ ratio has a strong and very strong relationship with Ridel-Garcia Intensity $I_{R-G}$ and Fafjar Intensity $I_{F}$. Furthermore, the A / V ratio has a moderate relationship with Housner intensity, $\mathrm{I}_{\mathrm{H}}$

Between significant duration D595 (or effective duration $t_{e}$ ) with damage index DI has a positive relationship, meaning that the longer the duration of the earthquake tends to progressively cause damage to the building. A similar relationship also occurs between the numbers of plastic hinge occurrence with the damage index DI. However, the relationship between the two is still a weak correlation. On the other hand, the contribution of dissipated hysteretic energy to the index of damage ranges from $0.9-36.8 \%$ with an average of $12.9 \%$.

Other results also show that in the ductile element, the ductility ratio is strongly related and contributes more to the damage index than the disseminated hysteretic energy. In addition to the ductility ratio, the peak of PSA also has a very strong relationship with the damage index. The effect of the frequency ratio on the structure response is very apparent which is indicated by an earthquake that has a very low-frequency content it only leads to low structural response.

\section{References}

1. H. Sucuoglu and A. Nurtug, Earthquake ground motion characteristics and seismic energy dissipation, Earthq. Eng. Struct. Dyn., Vol. 24, no. 9, pp. 1195-1213, (1995).

2. R. Riddel, Correlation between ground motion intensity indices and structural response, Department of Structural and Geotechnical Engineering, UniversidadnCatolica de Chile, (2005)

3. L. Danciu, Development of a system to assess the earthquake damage potential for buildings : Intensiometer Development of a System to Assess the Earthquake Damage Potential for Buildings : Intensiometer, Univ.of Patras, 253p, (2006.).

4. L.Ye, Q.Ma, Z.Miao, H.Guan, Y Zhuge, Numerical and comparative study of 
earthquake intensity indices in seismic analysis, The structural design of tall and special building, DOI: 10.1002/tal/693, (2011)

5. N. Buratti., "A comparison of the performances of various ground-motion intensity measures," Proc. 15th World Conf. Earthq. Eng., pp. 1-10, (2012).

6. Y. Cheng, Intensity Measures for Seismic Response Prediction and associated Ground Motion Selection and Modification, Universitas Roma La Sapienza, (2013).

7. H.A.D.K Buddika, A.C. Wijeyewickrema, Effects of earthquake ground motion duration on reinforced concrete buildings, $4^{\text {th }}$ Multidisplinary International Student Workshop, Tokyo Institute of Technology, (2012).

8. M. Raghunandan, A.B.Liel, Effects of earthquake ground motion duration on earthquake induce structural collapse, Structural Safety, Vol.41, pp.119-133, (2013).

9. R Chandramohan, J.W Baker, G.G Dierlein, Quantifying the influence of ground motion duration on structural collapse capacity using spectrally equivalent records, Dept. of Civil Environmental Engineeiung, Stanford University, CA 94305, (2014)

10. A.R Barbosa, F.L.A Ribeiro, L.A.C Neves, Influence of earthquake ground motion duration on Damage estimation : Application to steel moment resisting frame, submitted to Earthquake Engineering and Structural Dynamics, (2016)

11. M.D Trifunac, A.G Brady, a Study on the duration of strong earthquake ground motion, Bulletin of the Seismological Society of America, Vol.65, No.3, pp.581-626, (1975)

12. J.J. Bommer, A.M Pereira, The effective duration of earthquake strong motion, J.of Earthq. Eng, Vo.3, No.2, pp.127-172, (1999).

13. J.Th Snaebjornsson, R Sigbjornsson, The duration characteristics of earthquake ground motions, The $14^{\text {th }}$ World Conference on Earthquake Engineering, Beijing, China, (2008),

14. J.J Kempton, J.P Stewart, Prediction equations for significant duration of earthquake ground motions considering site and near source effects, Earthquake Spectra, Vol.22, pp.985-1013, (2006)

15. S Ghalat, Duration Characteristics of the Mean Horizontal Component of Shallow Crustal earthquake Records at Active Tectonic Regions, PhD Dissertation, Arizona State University, 214p, (2011)

16. B.Hernandez, A.F.Cotton, Empirical determination of the ground shaking duration due to an earthquake using strong motion acceleration for engineering application, $12^{\text {th }}$ WCEE, New Zealand, (2000)

17. S.Y. Sabegh, Z Shoghian, M.N Sheikh, A new model for the prediction of earthquake ground motion duration in Iran, Submitted to Natural Hazards, (2014)

18. Y.T Lee, K.F.Ma, Y.J Wang, K.L.Wen, An emprirical equation of effective shaking duration for moderate to large earthquake, Nat. Hazards, Vol.75, pp.1779-1793, (2015)

19. P Dong, Effects of varying hysteretic model s and damage models on damage assessment of RC structure s under standard design level earthquakes obtained using new scaling method, $\mathrm{PhD}$ thesis Department of Civil Engineering, University of Canterbury, Christchurch New Zealand, 2003, 226p.

20. A. J. Carr, Ruaumoko Theory, Comput. Progr. Libr., Vol. 1, 87p, (2007).

21. R.Sinha, S.R.Shiradhonkar, Seismic Damage Index for classification of structural damage, The $15^{\text {th }}$ WCEE, Lisboa, (2012)

22. M.Mihai, A theoretical review of the damage indices used to model the dynamic nonlinear behavior of reinforced concrete structures, Buletinul Institutului Pilitehnic Din Aisi, (2013) 
23. V.V.Chao, H.Ronach, M Ashraf, H.Baji, , A New damage index for reinforced concrete structures subjected to seismic loads, School of Civil Engineering University of Queensland, Australia, (2015).

24. T Paulay, M.J.N. Priestley, Seismic design of reinforced concrete and masonry buildings, John Wiley and Sons, Inc., 774p, (1992).

25. W. K. Tso, T. J. Zhu, and A. C. Heidebrecht, Engineering implication of ground motion A / V ratio, Soil Dyn. Earthq. Eng., Vol. 11, pp. 133-144, (1992).

26. E.Ozer, S Soyoz, M.Celebi, Effects of strong motion duration on structural dmage, The $15^{\text {th }}$ WCEE, Lisboa, (2012).

27. A.G Asuero, A. Sayago, A.G Gonzales, The Correlation coefficient: An Overview, Critical Review in Analytical Chemistry, Vol.36,pp 41-59, (2006). 